\title{
Injection mold design for the bottle cap of facial cleanser \\ Peiyun.Ao
}

\begin{abstract}
Xinyu University of Mechanical Engineering, 2666 Sunshine Avenue ,high tech Zone of Xinyu,Jiangxi 338004 ,China
\end{abstract}

514149150@qq.com

Keywords: Face wash bottle, ABS, Injection mould, Pro/ENGINEER, Local inlay type concave die.

\begin{abstract}
According to the structural characteristics of the bottle cap, this paper analyzes the structure and the key technology of the die design; Respectively, using Moldwizard module and Pro/E mold design facial cleanser injection molding mold design, local mosaic of concave die design is proposed.
\end{abstract}

\section{Introduction}

Facial cleanser is the daily necessities, is commonly used in the daily life of the product, the more often life in the product design to the design of the people's life improvement is obvious. This design comes from life, it is widely used, but it is difficult to form, and the mould structure is complex. With the development of society, plastic products production and life has become increasingly close, plastic mold of the application is extremely broad, position in all kinds of mold is more and more outstanding, become one of the most representative of the significance of the mold of of all kinds of mold design, manufacturing and research.

\section{Process analysis of plastic parts}

\section{Facial milk bottle cap part drawing.}

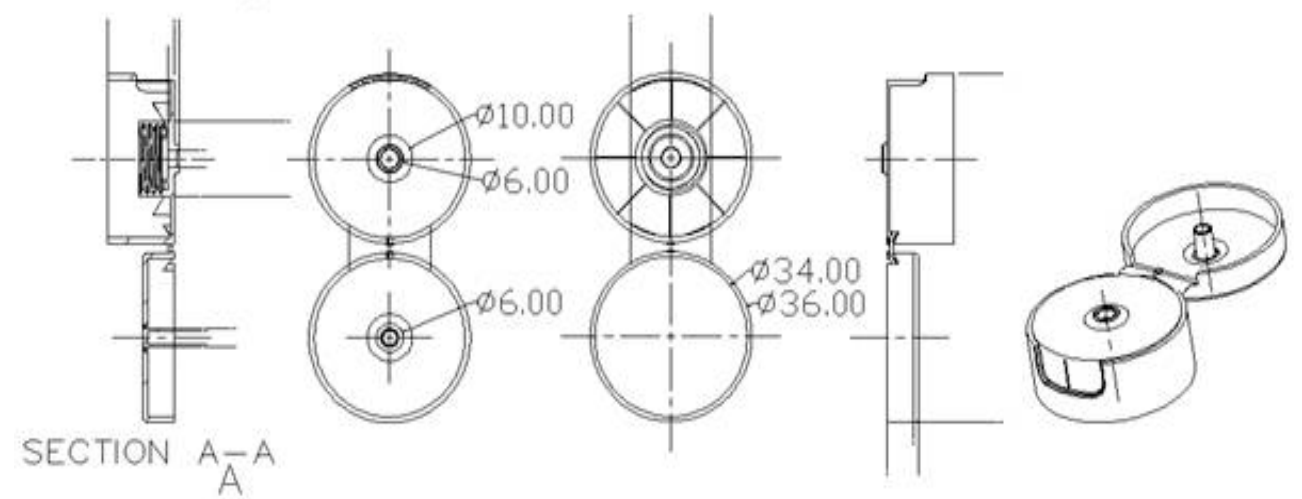

Fig.1 Basic size and shape of plastic parts

From the figure 1, the plastic parts for the facial cleanser, thin wall and complex parts, divided into two parts, through the arc slices and strengthen the connection, with the tension of smooth switching arc, So the plastic material with good anti fatigue and toughness, the lower part of the inner screw thread is arranged should be matched with the bottle body, and borrows the thread rod out of the plastic parts, the motion through the oil cylinder drives the gear movement; In addition, there is also a eight ribs, two of them mainly to strengthen the tendons, height and thickness were greater than the other six; micro convex and upper part slightly concave part design is matched with the positioning, the plastic surface of the work piece are processed into a rounded so as to avoid scratching the user. The product for daily necessities, the surface requires smooth, colour is 
gorgeous, does not allow forming spots and weld lines and dimension tolerance set for T5 level; the product is mainly used for sealing liquid and colloid, so the middle two parts with interference fit appropriate, the upper and lower part of the closed, to facilitate central with the uplift of the lower part shall be poured on certain fillet.

Plastic material selection and formulation. This product is made of styrene butadiene acrylonitrile (ABS) material. ABS with moisture absorption, in order to ensure the quality of the product, forming the front, must be fully dry raw materials. Drying method can be used in the hopper dryer (temperature $70 \sim 85,2 \mathrm{~h}$ ). After drying the moisture content should be no more than $0.1 \%$.

Table1 Injection process parameters of ABS

$\begin{aligned} & \text { Injection machine type } \\ & \text { Screw speed / }(\mathrm{r} / \mathrm{min})\end{aligned}$
$\begin{aligned} & \text { Nozzle } \\ & \text { type } \\ & \text { temperature } /{ }^{\circ} \mathrm{C} \\ & \text { forepart } \\ & \text { midpart } \\ & \text { afterpart }\end{aligned}$
temperature $/{ }^{\circ} \mathrm{C} \quad$
Mould temperature $/{ }^{\circ} \mathrm{C}$
Injection pressure $/ \mathrm{MPa}$
Protect pressure $/ \mathrm{MPa}$
Injection time $/ \mathrm{s}$
Holding time $/ \mathrm{s}$
Cooling time $/ \mathrm{s}$
Molding cycle $/ \mathrm{s}$

Screw type

$30 \sim 60$

Straight through

$180 \sim 190$

$200 \sim 210$

$210 \sim 230$

$180 \sim 200$

$50 \sim 80$

$70 \sim 90$

$50 \sim 70$

$3 \sim 5$

$15 \sim 30$

$15 \sim 30$

$40 \sim 70$

\section{Design of injection mold for facial cleanser}

The choice of parting surface and the determination of the number of cavities. To ensure that the plastic parts quality and avoid affecting the quality of appearance; for that part of the opening and closing of the smooth and cooperation. All the products into the parting surface are on the same side of the, to ensure that the plastic parts of the coaxial degree. In order to make the mold and injection machine production capacity matching, improve productivity and economy, and to ensure the accuracy of parts, using a multi cavity mode. Determine the number of cavity according to the maximum injection volume of injection machine, the formula:

$\mathrm{n}<=(0.8 \mathrm{G}-\mathrm{W} 2) / \mathrm{W} 1=(0.8 \times 120-71.454) / 1.41=17.4$

$\mathrm{n}$ take 8 using a eight cavity mold of circular array.

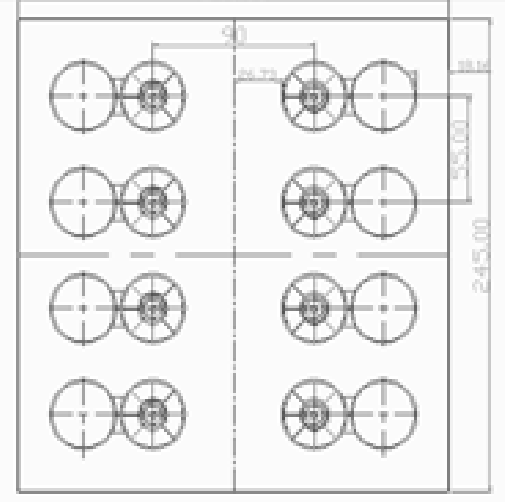

Fig.2 Model of cavity

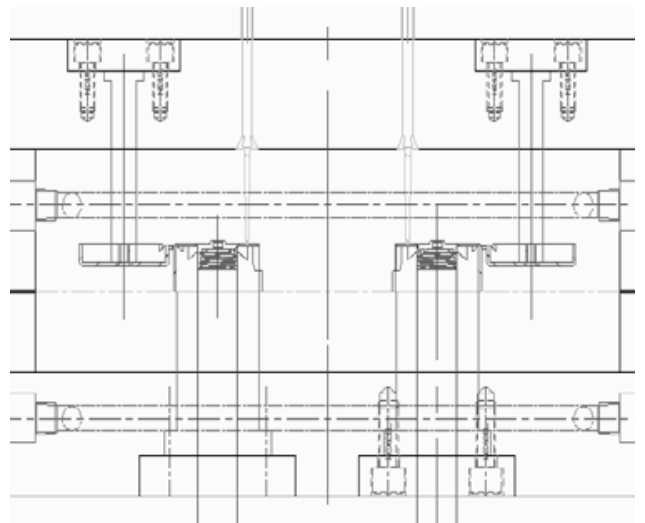

Fig.3 Insert parts 
Choice of injection machine. By the number of cavity, the preliminary selection of domestic XS-ZY250 type (a) injection moulding machine and the injection machine maximum injection quantity can reach $450 \mathrm{~cm} 3$, injection pressure of 130 , the clamping force can be reached $1650 \mathrm{KN}$, the mold board stroke can achieve $350 \mathrm{~mm}$.

Insert parts. This product structure is more complex and thin wall plastic parts, some of the processing surface is easy to damage, so it is difficult to make some difficult or easy to damage parts of the site. The design of punch and die with insert, insert size according to the size of the products of the, insert bottom are generally equipped with a boss for fixed and preventing rotation of the insert, template between must be separately, so in the insert bottom equipped with inlay piece fixing plate and screw fixation.

The structure of the injection mould design. This product is thin wall plastic parts, thin wall part is difficult to process, so this mold adopts the local inlay type die. Opening way: first the moving parts template will be completely out of pin, moves to the parting direction $102 \mathrm{~mm}$. Finally, the ejection mechanism will make a top, complete the opening process. The mold has the advantages of simple process, province mold process, high production efficiency. Frame select nozzle mold, using fine nozzle system, type I.
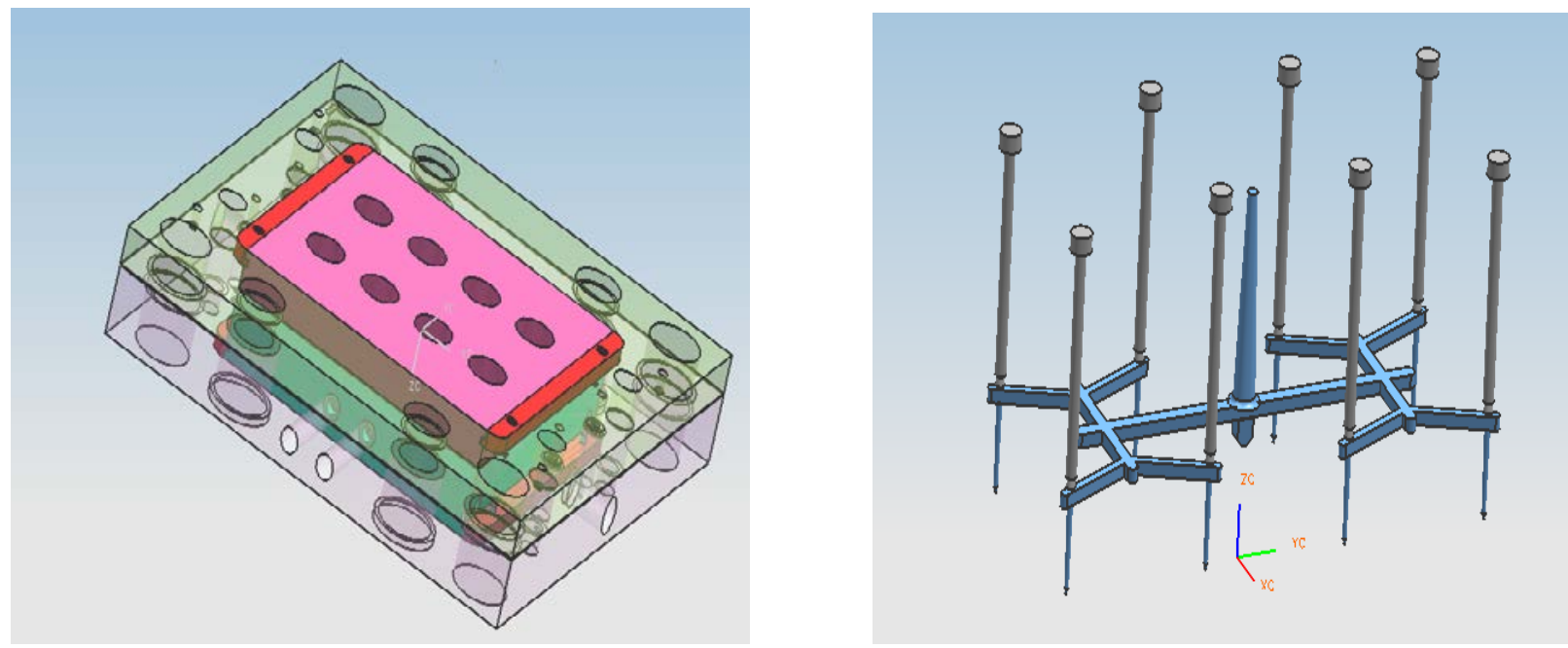

Fig.4 Schematic diagram

Fig.5 The layout of the runner, the runner and the part

Determination of modulus. Plastic parts molding surface are placed on the front mold, the diameter of the water initially set $8 \mathrm{~mm}$, finally determine the upper die kernel at the height of the $45.5 \mathrm{~mm}$ ( $1 \mathrm{~mm}$ gap between the template); finally determine the mold insert size is $240 \mathrm{~mm} \mathrm{x}$ $245 \mathrm{~mm}$. general mode kernel is a screw fixation in the template, taking into account the passage placed and congeals the material removal, the design of the mould kernel are designed to be like a template thickness, between them through the battens fixed.

Design of gating system. 1 . Gate design.The mold is a mold gate with double parting surface, so the pour point feed, one is in order to facilitate the plastic parts and condensation material separation, ease of automation production; using pour point can significantly improve the melt shear rate of ABS material, is conducive to mold, and remove the gate after the residual traces of small, easy to obtain the balance of the gate system.

2. Design of runner. 1). Mainstream channel design. The main channel is usually located at the entrance of the plastic melt at the center of the mold, which is injected into the flow channel or cavity of the injection mold. The sprue is in a conical shape, so that the melt flow and mold sprue pulling out smoothly. 2). Design of diversion channel and cold material well. Due to the use of the nozzle plate, the diversion channel must be made into a trapezoidal cross section, which is convenient for the diversion channel and the mainstream way. The trapezoidal top edge width takes 
$4 \mathrm{~mm}$, the trapezoidal channel is made of 10 degree angle with the direction of the vertical parting surface.

Cooling system design. The product for thin wall plastic parts, so only the ordinary unilateral around the circulating water can be, in the design between two symmetrical product distance $90 \mathrm{~mm}$ (center distance more than $70 \mathrm{~mm}$, general water still have to in $8 \mathrm{~mm}$ ) considering the product for thin wall plastic parts here waterway diameter set $8 \mathrm{~mm}$. The maximum height of the product is $45 \mathrm{~mm}$, and the maximum height of the product is $16.168 \mathrm{~mm}$.

\section{Injection mold 3D assembly and 3D explosion}

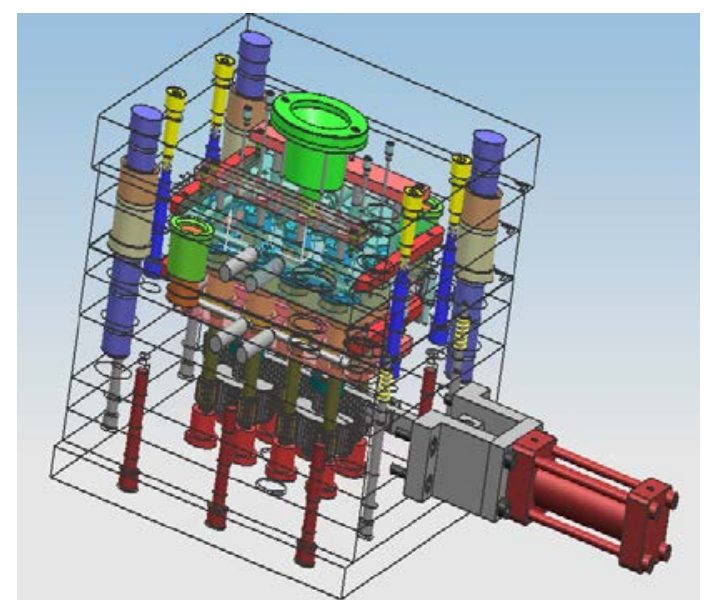

Fig.6 3D assembly

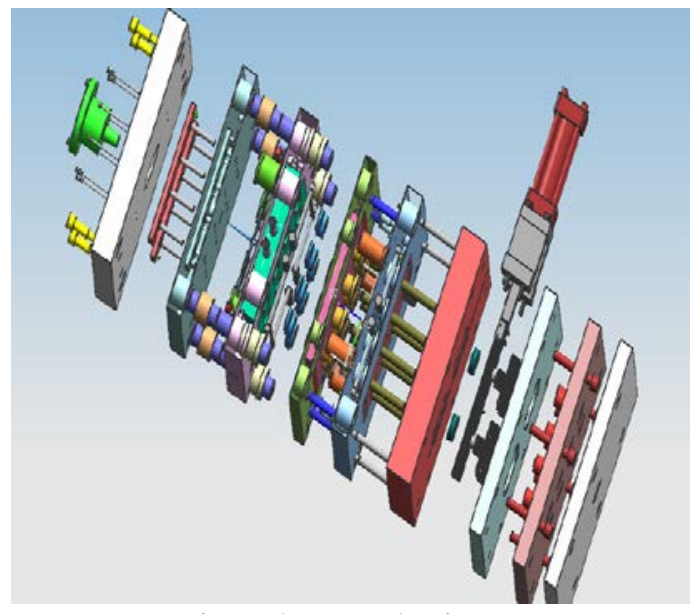

Fig.7 3D explosion

\section{References}

[1] J.G.Rong,.UG NX4.0 Chinese version introduction and improvement: Tsinghua University press

[2] Y. Zhao, et al. Manufacturing and manufacturing technology. Beijing: Tsinghua University press, 2006.05

[3] X.J.Qi et al. Plastic molding technology and die design (Second Edition). Mechanical Industry Press, 2012.5 